\title{
Pengembangan Modifikasi Permainan Lay Up dalam Pembelajaran Bola Basket untuk Kelas VIII SMP Negeri 5 Lamongan
}

\author{
Cerebri Brilian, Febrita Paulina Heynoek*, Gema Fitriady \\ Universitas Negeri Malang, Jl. Semarang No. 5 Malang, Jawa Timur, Indonesia \\ *Penulis korespondens, Surel: febrita.paulina.fik@um.ac.id
}

Paper received: 6-2-2022; revised: 24-2-2022; accepted: 29-2-2022

\begin{abstract}
The purpose of this research is to develop a learning modification of the shooting lay up game with audio-visual media as a support tool and to determine the validity of game modification with audiovisual media on the basic technique of shooting lay up. This research is a research and development research. Data from the evaluation results of Media Experts obtained that the average validity of the audio-visual media product in the form of a video modification of the lay up game in basketball learning was $95 \%$ which explained that the product was very valid and very feasible to use. From the evaluation data of the Physical Education Learning Experts, it was found that the average validity of the audio-visual media product in the form of a video modification of the lay-up game in basketball learning was $84 \%$ which explained that the product was quite valid and feasible to use. From the data from the basketball expert evaluation, it was found that the average validity of the audio-visual media product in the form of a video modification of the lay-up game in basketball learning was $98 \%$ which explained that the product was very valid and very feasible to use.
\end{abstract}

Keywords: modifikasi permainan; lay up; pembelajaran bola basket

\begin{abstract}
Abstrak
Tujuan dalam penelitian ini adalah untuk mengembangkan pembelajaran modifikasi permainan shooting lay up dengan media audio visual sebagai sarana penunjang serta untuk mengetahui validitas modifikasi permainan dengan media audio visual pada materi teknik dasar shooting lay up. Penelitian ini merupakan penelitian pengembangan atau research and development. Data hasil evaluasi Ahli Media diperoleh rata-rata validitas produk media audio visual yang berbentuk video modifikasi permainan lay up dalam pembelajaran bola basket sebesar $95 \%$ yang menjelaskan bahwa produk sangat valid dan sangat layak untuk digunakan. Dari data hasil evaluasi Ahli Pembelajaran Pendidikan Jasmani diperoleh rata-rata validitas produk media audio visual yang berbentuk video modifikasi permainan lay up dalam pembelajaran bola basket sebesar $84 \%$ yang menjelaskan bahwa produk cukup valid dan layak untuk digunakan. Dari data hasil evaluasi Ahli Basket diperoleh ratarata validitas produk media audio visual yang berbentuk video modifikasi permanan lay up dalam pembelajaran bola basket sebesar $98 \%$ yang menjelaskan bahwa produk sangat valid dan sangat layak untuk digunakan.
\end{abstract}

Kata kunci: game modificaton; lay up; basketball lessons

\section{Pendahuluan}

(Husdarta, 2011). Artinya, pendidikan jasmani tidak hanya suatu ornamen atau dekorasi pada program di sekolah tetapi juga sebagai alat agar membuat anak sibuk, oleh karena itu pendidikan jasmani adalah bagian penting dari suatu pendidikan yang diarahkan secara teratur, anak dapat mengembangkan keterampilan untuk pengisian waktu senggangnya, terlibat dalam aktivitas yang baik untuk mengembangkan hidup yang sehat, dan berkembang 
secara sosial dan menyumbang pada kesehatan fisik maupun mentalnya. Sama seperti pendidikan jasmani menurut UNESCO (dalam Mu'arifin,2009) "pendidikan jasmani merupakan proses dalam pendidikan seseorang, sebagai anggota masyarakat maupun individu yang dilakukan melalui berbagai kegiatan jasmani dalam rangka memperoleh peningkatan kemampuan pertumbuhan kecerdasan, penampilan jasmani, dan pembentukan watak secara sistematik". Maka dari itu pendidikan jasmani di sekolah dapat dibentuk melalui kepribadian peserta didik yang dimilikinya.

Pembelajaran pendidikan jasmani di sekolah menuntut seorang guru dalam menyampaikan suatu materi agar lebih kreatif, inovatif, efektif, karena itu perlu adanya suatu pengembangan model permainan dalam suatu pembelajaran yang sesuai dengan karakteristik usia mereka yang cenderung suka bermain. Selain itu guru harus lebih memperhatikan maupun memahami kebutuhan dan karakteristik peserta didik, pada masa usia tersebut seluruh aspek perkembangan peserta didik baik itu kognitif, psikomotorik, maupun afektik akan mengalami suatu perubahan. Dari perubahan - perubahan tersebut, perubahan yang paling menonjol yaitu pertumbuhan dan perkembangan fisik serta psikologisnya, (Mulyasa, 2007).

Sejalan dengan penelitian terdahulu yang sudah dilakukan oleh Rigananda (2017) yang berjudul Pengembangan Model Permainan Lay Up Dalam Pembelajaran Bola Basket Untuk Kelas VIII SMP Negeri Krejengan Kabupaten Probolinggo. Dalam penelitiannya model permainan lay up mendapat $85 \%$ dan layak digunakan pembelajaran dikelas. Berdasarakan hasil penelitian penelitian terdahulu yang dilakukan oleh (Cahyanto \& Hidayat, 2015), "modifikasi permainan membawa perubahan terhadap hasil belajar passing atas dengan peningkatan 6,60\%". Seperti yang disampaikan Rahma pada penelitiannya (tanpa tahun:173). "kemampuan motorik kasar anak dapat ditingkatkan melalui modifikasi permainan bola basket". Berdasarkan penelitian terdahulu dapat dilihat bahwa modifikasi permainan memiliki pengaruh dalam pembelajaran peserta didik.

Berdasarkan pengamatan secara langsung terdapat beberapa peserta didik SMP Negeri 5 Lamongan kelas VIII yang tidak menguasai teknik dengan benar dan mengalami kesulitan dalam memasukkan bola ke dalam ring khususnya teknik lay up pembelajaran bola basket yang diberikan oleh guru, sehingga peneliti perlu adanya suatu hal baru agar peserta didik lebih mudah dalam mempelajari gerakan tersebut. Dengan adanya keterbatasan waktu dalam pembelajaran diperlukan media audio visual untuk menunjang pemahaman peserta didik terhadap teknik gerakan lay up. Penggunaan media audio visual dalam pembelajaran di dalam kelas bisa bermanfaat untuk memotivasi peserta didik dalam meningkatkan hasil belajar yang dicapai baik berupa pengetahuan (kognitif), keterampilan (psikomotorik), maupun sikap (afektif), dan Media audio visual juga dapat dimanfaaatkan untuk memotivasi peserta didik dalam belajar di kelas dan diluar kelas agar mendapat pengalaman dalam mengamati tayangan media audio visual.

\section{Metode}

Metode penelitian dan pengembangan adalah sebuah metode yang akan menghasilkan suatu produk tertentu melalui research yang dilakukan peneliti menggunakan angket analisis kebutuhan yang diberikan kepada guru pendidikan jasmani beserta peserta didik kelas VIII SMP Negeri 5 Lamongan guna mengetahui kebutuhan pengguna. Setelah dilakukan research 
maka selanjutnya adalah development yaitu proses pembuatan produk sesuai dengan kebutuhan berdasarkan angket analisis kebutuhan.

Penelitian dan pengembangan ini akan dilakukan sampai tahap keempat, hanya berhenti pada validasi ahli saja dikarenakan adanya pandemi Covid-19 yang belum selesai sampai dengan sekarang. Penelitian dan pengembangan ini bertujuan menghasilkan suatu produk berupa modifikasi permainan lay up materi bola basket yang nanti dikemas dalam bentuk media audio visual. Penelitian ini akan dilakukan di SMP Negeri 5 Lamongan yang beralamat di Jl. Raya Tanjung Kabupaten Lamongan. Subjek yang dipakai dalam penelitian ini adalah peserta didik kelas VIII SMP Negeri 5 Lamongan.

Analisis data dalam penelitian ini menggunakan rumus sebagai berikut.

$$
V=\frac{T S E V}{s-M a x} X 100 \%
$$

\section{Hasil dan Pembahasan}

Data hasil evaluasi ahli ini diperoleh peneliti berdasarkan instrumen validasi berupa angket 20 butir soal terkait video modifikasi permainan lay up dalam pembelajaran bola basket yang diisi oleh ahli media yaitu Eka Pramono Adi, S.IP, M.Si, dosen dari Fakultas Ilmu Pendidikan. Data hasil evalusai ahli media dapat dilihat pada Tabel 1.

Tabel 1. Data Hasil Evaluasi Ahli Media

\begin{tabular}{|c|c|c|c|c|c|c|}
\hline No & Indikator & No Butir & TSEV & $\begin{array}{l}\text { S } \\
\text { Max }\end{array}$ & V\% & Keterangan \\
\hline 1 & Pembukaan media audio visual & 1,2 & 8 & 8 & $100 \%$ & $\begin{array}{l}\text { Sangat } \\
\text { valid }\end{array}$ \\
\hline 2 & $\begin{array}{l}\text { Tampilan gambar pada media } \\
\text { audio visual }\end{array}$ & 3 & 4 & 4 & $100 \%$ & $\begin{array}{l}\text { Sangat } \\
\text { valid }\end{array}$ \\
\hline 3 & $\begin{array}{l}\text { Tampilan judul pada media } \\
\text { audio visual }\end{array}$ & 4 & 4 & 4 & $100 \%$ & $\begin{array}{l}\text { Sangat } \\
\text { valid }\end{array}$ \\
\hline 4 & $\begin{array}{l}\text { Penggunaan backsound dan } \\
\text { thumbnail dalam media audio } \\
\text { visual }\end{array}$ & $5,6,7,8$ & 15 & 16 & $94 \%$ & $\begin{array}{l}\text { Sangat } \\
\text { valid }\end{array}$ \\
\hline 5 & $\begin{array}{l}\text { Penggunaan kesesuaian } \\
\text { thumbnail, intro dan backsound } \\
\text { di dalam media audio visual }\end{array}$ & 9 & 4 & 4 & $100 \%$ & $\begin{array}{l}\text { Sangat } \\
\text { valid }\end{array}$ \\
\hline 6 & $\begin{array}{l}\text { Penggunaan petunjuk, tema dan } \\
\text { persiapan dalam pembelajaran } \\
\text { media audio visual }\end{array}$ & $10,11,12$ & 10 & 12 & $83 \%$ & $\begin{array}{l}\text { Cukup } \\
\text { valid }\end{array}$ \\
\hline 7 & Tampilan letak slowmotion & 13 & 4 & 4 & $100 \%$ & $\begin{array}{l}\text { Sangat } \\
\text { valid }\end{array}$ \\
\hline 8 & $\begin{array}{l}\text { Penggunaan kesesuaian suara } \\
\text { peneliti dengan backsound } \\
\text { dalam media audio visual }\end{array}$ & 14 & 4 & 4 & $\begin{array}{l}100 \\
\%\end{array}$ & $\begin{array}{l}\text { Sangat } \\
\text { valid }\end{array}$ \\
\hline 9 & $\begin{array}{l}\text { Kejelasan video pembelajaran } \\
\text { modifikasi permainan lay up }\end{array}$ & 15 & 4 & 4 & $100 \%$ & $\begin{array}{l}\text { Sangat } \\
\text { valid }\end{array}$ \\
\hline 10 & $\begin{array}{l}\text { Kesesuaian media untuk guru } \\
\text { dan peserta didik kelas VIII SMP } \\
\text { Negeri } 5 \text { Lamongan }\end{array}$ & 16,17 & 8 & 8 & $100 \%$ & $\begin{array}{l}\text { Sangat } \\
\text { valid }\end{array}$ \\
\hline 11 & $\begin{array}{l}\text { Pengoperasian media untuk guru } \\
\text { dan peserta didik kelas VIII SMP } \\
\text { Negeri } 5 \text { Lamongan }\end{array}$ & 18,19 & 8 & 8 & $88 \%$ & $\begin{array}{l}\text { Cukup } \\
\text { valid }\end{array}$ \\
\hline
\end{tabular}




\begin{tabular}{lllllll}
\hline 12 & Kelayakan media audio visual & 20 & 4 & 4 & $100 \%$ & $\begin{array}{l}\text { Sangat } \\
\text { valid } \\
\text { Jumlah }\end{array}$ \\
& 76 & 80 & $95 \%$ & $\begin{array}{l}\text { Sangat } \\
\text { valid }\end{array}$ \\
\hline
\end{tabular}

Berdasarkan Tabel 1 evaluasi ahli media terhadap produk media audio visual modifikasi permainan lay up dalam pembelajaran bola basket untuk kelas VIII SMP Negeri 5 Lamongan telah diperoleh hasil sebagai berikut: (1)terkait dengan pembukaan media audio visual diperoleh $100 \%$ dengan keterangan sangat valid, (2) tampilan gambar pada media audio visual diperoleh 100\% dengan keterangan sangat valid, (3) tampilan judul diperoleh 100\% dengan keterangan sangat valid, (4) penggunaan backsound dan thumbnail diperoleh $94 \%$ dengan keterangan sangat valid, (5) penggunaan kesesuaian thumbnail, intro dan backsound diperoleh $100 \%$ dengan keterangan sangat valid, (6) penggunaan petunjuk, tema, dan persiapan dalam pembelajaran media audio visual diperoleh $83 \%$ dengan keterangan cukup valid, (7) tampilan letak slowmotion diperoleh 100\% dengan keterangan sangat valid, (8) penggunaan kesesuaian suara peneliti dengan backsound diperoleh 100\% dengan keterangan sangat valid, (9) kejelasan video pembelajaran modifikasi permainan lay up diperoleh $100 \%$ dengan keterangan sangat valid, (10) kesesuaian media untuk untuk guru dan peserta didik kelas VIII SMP Negeri 5 Lamongan diperoleh 100\% dengan keterangan sangat valid, (11) pengoperasian media untuk guru dan peserta didik diperoleh $88 \%$ dengan keterangan sangat valid, (12) kelayakan media audio visual diperoleh 100\% dengan keterangan sangat valid. Dari 12 indikator tersebut diperoleh rata-rata validitas produk media audio visual modifikasi permainan lay up dalam pembelajaran bola basket untuk kelas VIII SMP Negeri 5 Lamongan sebesar 95\% yang menjelaskan bahwa produk sangat valid dan sangat layak untuk digunakan.

Data hasil evaluasi ahli ini diperoleh peneliti berdasarkan instrumen validasi berupa angket dengan 20 butir soal terkait modifikasi permainan lay up dalam pembelajaran bola basket yang diisi oleh ahli pembelajaran pendidikan jasmani yaitu Rama Kurniawan, M. Pd, dosen dari Fakultas Ilmu Keolahragaan. Data hasil evalusai ahli pembelajaran dapat dilihat pada Tabel 2.

Tabel 2. Data Hasil Evaluasi Ahli Pembelajaran

\begin{tabular}{|c|c|c|c|c|c|c|}
\hline No & Indikator & $\begin{array}{l}\text { No } \\
\text { Butir }\end{array}$ & $\begin{array}{l}\mathrm{T} \\
\text { SEV }\end{array}$ & $\begin{array}{l}\text { S- } \\
\text { Max }\end{array}$ & V\% & Keterangan \\
\hline 1 & $\begin{array}{l}\text { Pembukaan pembelajaran bola } \\
\text { basket }\end{array}$ & 1 & 3 & 4 & $75 \%$ & $\begin{array}{l}\text { Cukup } \\
\text { valid }\end{array}$ \\
\hline 2 & $\begin{array}{l}\text { Kegiatan pembelajaran cakupan } \\
\text { materi, sarana dan prasarana, serta } \\
\text { video dalam modifikasi permainan } 1\end{array}$ & $2,3,4$ & 10 & 12 & $83 \%$ & $\begin{array}{l}\text { Cukup } \\
\text { valid }\end{array}$ \\
\hline 3 & $\begin{array}{l}\text { Kegiatan pembelajaran cakupan } \\
\text { materi, sarana dan prasarana, serta } \\
\text { video dalam modifikasi permainan } 2\end{array}$ & $5,6,7$ & 10 & 12 & $83 \%$ & $\begin{array}{l}\text { Cukup } \\
\text { Valid }\end{array}$ \\
\hline 4 & $\begin{array}{l}\text { Kegiatan pembelajaran cakupan } \\
\text { materi, sarana dan prasarana, serta } \\
\text { video dalam modifikasi permainan } 3\end{array}$ & $\begin{array}{l}8,9 \\
10\end{array}$ & 9 & 12 & $75 \%$ & $\begin{array}{l}\text { Cukup } \\
\text { valid }\end{array}$ \\
\hline 5 & $\begin{array}{l}\text { Kegiatan pembelajaran cakupan } \\
\text { materi, sarana dan prasarana, serta } \\
\text { video dalam modifikasi permainan } 4\end{array}$ & $\begin{array}{l}11, \\
12, \\
13\end{array}$ & 11 & 12 & $92 \%$ & $\begin{array}{l}\text { Sangat } \\
\text { Valid }\end{array}$ \\
\hline 6 & $\begin{array}{l}\text { Kegiatan pembelajaran cakupan } \\
\text { materi, sarana dan prasarana, serta } \\
\text { video dalam modifikasi permainan } 5\end{array}$ & $\begin{array}{l}14 \\
15 \\
16\end{array}$ & 12 & 12 & $100 \%$ & $\begin{array}{l}\text { Sangat } \\
\text { valid }\end{array}$ \\
\hline
\end{tabular}




\begin{tabular}{lllllll}
\hline No & Indikator & $\begin{array}{l}\text { No } \\
\text { Butir }\end{array}$ & $\begin{array}{l}\text { T } \\
\text { SEV }\end{array}$ & $\begin{array}{l}\text { S- } \\
\text { Max }\end{array}$ & V \% & Keterangan \\
\hline 7 & 17 & 3 & 4 & $75 \%$ & $\begin{array}{l}\text { Cukup } \\
\text { valid }\end{array}$ \\
\hline $\begin{array}{l}\text { Kegiatan proses pembelajaran } \\
\text { modifikasi permainan lay up bola } \\
\text { basket untuk meningkatkan minat } \\
\text { siswa SMP Negeri 5 Lamongan }\end{array}$ & 18, & 6 & 8 & $75 \%$ & $\begin{array}{l}\text { Cukup } \\
\text { valid }\end{array}$ \\
\hline $\begin{array}{l}\text { Kegiatan pembelajaran dalam } \\
\text { penggunaan bahasa dan kesimpulan } \\
\text { dalam video modifikasi permainan } \\
\text { lay up bola basket }\end{array}$ & 19 & & & & & \\
\hline $\begin{array}{l}\text { Kelayakan pembelajaran modifikasi } \\
\text { permainan dalam pendidikan } \\
\text { jasmani olahraga kesehatan } \\
\text { Jumlah }\end{array}$ & 20 & 3 & 4 & $75 \%$ & $\begin{array}{l}\text { Cukup } \\
\text { valid }\end{array}$ \\
\hline
\end{tabular}

Berdasarkan Tabel 2 evaluasi ahli pembelajaran terhadap produk media audio visual modifikasi permainan lay up dalam pembelajaran bola basket untuk kelas VIII SMP Negeri 5 Lamongan telah diperoleh hasil sebagai berikut (1) pembukaan pembelajaran bola basket diperoleh 75\% dengan keterangan cukup valid, (2) kegiatan untuk pembelajaran cakupan materi, saran dan prasarana, serta video dalam modifikasi permainan 1 diperoleh $83 \%$ dengan keterangan cukup valid, (3) kegiatan untuk pembelajaran cakupan materi, saran dan prasarana, serta video dalam modifikasi permainan 2 diperoleh $83 \%$ dengan keterangan cukup valid, (4) kegiatan untuk pembelajaran cakupan materi, saran dan prasarana, serta video dalam modifikasi permainan 3 diperoleh 75\% dengan keterangan cukup valid, (5) kegiatan untuk pembelajaran cakupan materi, saran dan prasarana, serta video dalam modifikasi permainan 4 diperoleh 92\% dengan keterangan sangat valid, (6) kegiatan untuk pembelajaran cakupan materi, saran dan prasarana, serta video dalam modifikasi permainan 5 diperoleh $100 \%$ dengan keterangan sangat valid, (7) kegiatan proses pembelajaran modifikasi permainan lay up bola basket untuk meningkatkan minat siswa SMP Negeri 5 Lamongan diperoleh 75 dengan keterangan cukup valid, (8) kegiatan pembelajaran dalam penggunaan bahasa dan kesimpulan pada video modifikasi permainan lay up bola basket diperoleh $75 \%$ dengan keterangan cukup valid, (9) kelayakan pembelajaran modifikasi permainan dalam pendidikan jasmani olahraga kesehatan diperoleh 75\% dengan keterangan cukup valid. Dari 9 Indikator tersebut diperoleh rata-rata validitas produk media audio visual modifikasi permainan lay up dalam pembelajaran bola basket untuk kelas VIII SMP Negeri 5 lamongan sebesar $84 \%$ yang menjelaskan bahwa produk cukup valid dan layak untuk digunakan.

Data hasil evaluasi ahli ini diperoleh peneliti berdasarkan instrumen validasi berupa angket dengan 20 butir soal terkait modifikasi permainan basket yang diisi oleh ahli basket yaitu Errys Susetyo Nugroho, S. Pd, M. Pd pelatih basket klub Valcon Lamongan. Data hasil evalusai ahli basket dapat dilihat pada Tabel 3 .

Tabel 3. Data Hasil Evaluasi Ahli Basket

\begin{tabular}{lllllll}
\hline No & Indikator & No & TSEV & $\begin{array}{l}\text { S } \\
\text { BAX }\end{array}$ & V\% & Keterangan \\
\hline 1 & $\begin{array}{l}\text { Kegiatan isi materi modifikasi } \\
\text { permainan lay up bola basket }\end{array}$ & 1 & 4 & 4 & $100 \%$ & $\begin{array}{l}\text { Sangat } \\
\text { valid }\end{array}$ \\
2 & $\begin{array}{l}\text { Kegiatan variasi modifikasi } \\
\text { permainan bola basket }\end{array}$ & 2 & 4 & 4 & $100 \%$ & $\begin{array}{l}\text { Sangat } \\
\text { valid }\end{array}$ \\
\hline
\end{tabular}




\begin{tabular}{|c|c|c|c|c|c|c|}
\hline No & Indikator & $\begin{array}{l}\text { No } \\
\text { Butir } \\
\end{array}$ & TSEV & $\begin{array}{l}\text { S } \\
\text { MAX }\end{array}$ & V\% & Keterangan \\
\hline 3 & $\begin{array}{l}\text { Prosedur permainan, cara } \\
\text { pelaksanaan dan video untuk } \\
\text { meningkatkan lay up pada } \\
\text { permainan } 1\end{array}$ & $3,4,5$ & 12 & 12 & $100 \%$ & $\begin{array}{l}\text { Sangat } \\
\text { valid }\end{array}$ \\
\hline 4 & $\begin{array}{l}\text { Prosedur permainan, cara } \\
\text { pelaksanaan dan video untuk } \\
\text { meningkatkan lay up pada } \\
\text { permainan } 2\end{array}$ & $6,7,8$ & 12 & 12 & $100 \%$ & $\begin{array}{l}\text { Sangat } \\
\text { valid }\end{array}$ \\
\hline 5 & $\begin{array}{l}\text { Prosedur permainan, cara } \\
\text { pelaksanaan dan video untuk } \\
\text { meningkatkan lay up pada } \\
\text { permainan } 3\end{array}$ & $\begin{array}{l}9,10 \\
11\end{array}$ & 12 & 12 & $100 \%$ & $\begin{array}{l}\text { Sangat } \\
\text { valid }\end{array}$ \\
\hline 6 & $\begin{array}{l}\text { Prosedur permainan, cara } \\
\text { pelaksanaan dan video untuk } \\
\text { meningkatkan lay up pada } \\
\text { permainan } 4\end{array}$ & $\begin{array}{l}12, \\
13,14\end{array}$ & 12 & 12 & $100 \%$ & $\begin{array}{l}\text { Sangat } \\
\text { valid }\end{array}$ \\
\hline 7 & $\begin{array}{l}\text { Prosedur permainan, cara } \\
\text { pelaksanaan dan video untuk } \\
\text { meningkatkan lay up pada } \\
\text { permainan } 5\end{array}$ & $\begin{array}{l}15, \\
16,17\end{array}$ & 10 & 12 & $83 \%$ & $\begin{array}{l}\text { Cukup } \\
\text { valid }\end{array}$ \\
\hline 8 & $\begin{array}{l}\text { Kegiatan modifikasi permainan } \\
\text { dalam bentuk media audiovisual } \\
\text { untuk meningkatkan lay up bola } \\
\text { basket }\end{array}$ & 18,19 & 8 & 8 & $100 \%$ & $\begin{array}{l}\text { Sangat } \\
\text { valid }\end{array}$ \\
\hline \multirow[t]{2}{*}{9} & $\begin{array}{l}\text { Kesesuaian isi materi permainan } \\
\text { dengan audiovisual untuk peserta } \\
\text { didik kelas VIII }\end{array}$ & 20 & 4 & 4 & $100 \%$ & $\begin{array}{l}\text { Sangat } \\
\text { valid }\end{array}$ \\
\hline & Jumlah & & 78 & 80 & $98 \%$ & $\begin{array}{l}\text { Sangat } \\
\text { valid }\end{array}$ \\
\hline
\end{tabular}

Berdasarkan Tabel 3 evaluasi ahli basket terhadap produk media audio visual video modifikasi permainan lay up dalam pembelajaran bola basket kelas VIII SMP Negeri 5 Lamongan telah diperoleh hasil sebagai berikut (1) terkait dengan isi materi serta modifikasi permainan lay up bola basket diperoleh prosentase sebesar $100 \%$ dengan keterangan sangat valid, (2) variasi modifikasi permainan bola basket diperoleh prosentase $100 \%$ dengan keterangan sangat valid, (3) prosedur permainan, cara pelaksanaan dan video untuk meningkatkan lay up pada permainan 1 diperoleh 100\% dengan keterangan sangat valid, (4) prosedur permainan, cara pelaksanaan dan video untuk meningkatkan lay up pada permainan 2 telah diperoleh $100 \%$ dengan keterangan sangat valid, (5) prosedur permainan, cara pelaksanaan dan video untuk meningkatkan lay up pada permainan 3 diperoleh $100 \%$ dengan keterangan sangat valid, (6) prosedur permainan, cara pelaksanaan dan video untuk meningkatkan lay up pada permainan 4 telah diperoleh 100\% dengan keterangan sangat valid, (7) prosedur permainan, cara pelaksanaan dan video untuk meningkatkan lay up pada permainan 5 diperoleh 83\% dengan keterangan cukup valid, (8) kegiatan permainan bola basket dalam bentuk media audio visual video untuk meningkatkan lay up bola basket diperoleh 100\% dengan keterangan sangat valid, (9) kesesuaian isi materi permainan dengan media audio visual video untuk peserta didik kelas VIII telah diperoleh $100 \%$ dengan keterangan sangat valid. Dari 9 Indikator tersebut diperoleh rata-rata validitas produk media audio visual modifikasi permainan lay up dalam pembelejaran bola basket untuk kelas VIII SMP 
Negeri 5 Lamongan sebesar 98\% yang menjelaskan bahwa produk sangat valid dan sangat layak untuk digunakan.

Salah satu cabang permainan beregu dalam olahraga adalah bolabasket. Permainan ini dimainkan oleh dua tim yang beranggotakan lima orang pemain. Olahraga permainan ini juga bertujuan untuk memasukkan bola ke dalam ring basket lawan dengan cara mencetak angka sebanyak-banyaknya dan mencegah lawan agar tidak mendapatkan nilai (Sunarsih dkk, 2007). Permainan bolabasket merupakan suatu permainan sederhana yang mudah untuk dikuasai dan dipelajari dengan sempurna juga menuntut adanya melakukan latihan secara baik disiplin dalam rangka membentuk kerja dari tim tersebut Ahmadi (2007). Permainan ini juga menampilkan banyak hal seperti melakukan gerakan dribbling sambil meliuk-liuk, lalu ada juga tembakan (shooting) yang bervariasi, terobosan yang fantastik, dan gerakan yang penuh dengan tipu daya juga silih bergantinya gol yang sangat indah dari tim yang bermain.

Dalam permainan bolabasket terdapat teknik shooting yang mempunyai peranan yang vital dan dominan dalam permainan bola basket salah satunya tembakan lay up shoot. Menurut Rohim A, (2010) tembakan lay up shoot merupakan suatu tembakan dari jarak dekat yang dilakukan dengan keranjang, sehingga bola itu seolah-olah di letakkan ke dalam keranjang yang didahului dengan gerakan melangkah lebar lalu melompat dengan setinggi-tingginya. Adapun pendapat dari Nancy, Lieberman (2012) "Lay up harus menjadi tembakan yang pertama yang anda kuasai itu tembakan dengan presentasi tinggi". Dari pendapat diatas dapat disimpulkan bahwa lay up shoot merupakan suatu gerakan melompat dan melebar yang dilakukan dari jarak dekat bertujuan untuk mendapatkan poin dengan presentasi tinggi.

Modifikasi permainan diperlukan dalam suatu pembelajaran agar materi yang diberikan guru lebih menyenangkan dan juga agar pembelajaran lebih variatif. Modifikasi permainan lay up bola basket ini dikembangkan dari Kompentensi Inti (KI.2) yang menjelaskan bahwa peserta didik menunjukkan perilaku jujur, disiplin, tanggung jawab, peduli (toleransi, gotong royong), santun dan percaya diri dalam berinteraksi secara efektif dengan lingkungan sosial dan alam dalam jangkauan pergaulan dan keberadaannya. Modifikasi permainan yang dibuat oleh peneliti terdapat 5 jenis modifikasi permainan terdiri dari:

Confident Basketball Game yang bertujuan agar pemain lebih percaya diri dalam memasukkan bola kedalam ring yang sudah dimodifikasi. Menurut Justin Howard (2010) dalam jurnal (Kadek, S 2011) mengatakan bahwa kepercayaan diri dalam peserta didik bisa ditingkatkan melalui sebuah permainan, karena melalui permainan itu akan membentuk suatu dinamika kelompok secara efektif. Berdasarkan teori tersebut maka dalam tujuan permainan confident basketball game gerakan lay up dengan ring basket yang sudah dimodifikasi dengan hulla hop akan membuat siswa lebih percaya dan lebih efektif dalam memasukkan bola ke dalam ring.

Basketball Disclipinary Sharing Game permainan ini bertujuan untuk melatih kesabaran dan disiplin pemain dalam menunggu giliran memasukkan bola. Disiplin merupakan kesadaran diri seseorang yang berasal dari hati. Dengan disiplin pada diri seseorang maka akan disiplin juga dalam bentuk segala hal (Sugi Harni, Indana T 2018). Berdasarkan teori tersebut dikembangkan suatu modifikasi permainan basketball disclipinary sharing game yaitu dalam diri pemain harus memiliki kesadaran dari hati dalam menunggu giliran agar karakter disiplin bisa didapatkan dalam permaian ini. 
Concentration Basketball Games permainan ini bertujuan melatih konsentrasi pemain. Menurut (Nusufi, 2016) konsentrasi merupakan kemampuan dari seseorang agar dapat memusatkan perhatian pada rangsang yang dipilihnya (satu objek) dalam waktu yang singkat. Mengacu dari teori tersebut dapat dikembangkan permainan concencration basketball game yang terdapat gerakan sebelum memasukkan bola kedalam ring yang sudah dimodifikasi pemain memilih salah satu kun ke arah mana dia akan berlari yang menjadi indikator konsentrasi.

Cooperative Basketball Game permainan ini bertujuan untuk melatih kerjasama pemain. Kerjasama adalah suatu interaksi sosial anggota kelompok dimana tujuan itu berkaitan erat dengan tujuan kelompok lainnya sehingga seorang pemain hanya dapat mencapai tujuan jika pemain lain juga dapat mencapai tujuannya (Kurniawan D, 2015). Berdasarkan teori tersebut dapat dikembangkan permainan Cooperative basketball game yang mana dalam permainan tersebut diperlukan kerjasama tim yang tinggi agar tujuan dalam permain dapat tercapai dengan baik.

4 vs 4 Battle Lay Up permainan ini bertujuan untuk melatih kerjasama, toleransi, saling menghargai, percaya diri, disiplin. Menurut Kristiyandaru (2010) salah satu tujuan dari pendidikan jasmani bertujuan untuk mengembangkan sikap yang sportif, disiplin, jujur, kerjasama, bertanggung jawab, demokratis serta percaya diri melalui aktivitas jasmani permainan dan olahraga. Berdasarkan teori tersebut dapat dikembangkan permainan 4 vs 4 battle lay up yang mana pada permainan ini dapat membuat pemain dapat mengembangkan kepribadian, sikap maupun nilai-nilai yang sportif dalam bermain.

Produk pengembangan modifikasi permainan lay up dalam pembelajaran bola basket yang dikemas dalam media audio visual yang berbentuk CD ini dibuat dengan proses yang cukup panjang, mulai dari pembuatan produk video sesuai dengan langkah-langkah yang ada, kemudian mengkonsultasikannya kepada dosen pembimbing 1 dan dosen pembimbing 2 beserta ahli media, ahli pembelajaran pendidikan jasmani, dan ahli basket. Modifikasi permainan lay up bola basket dapat membuat siswa memahami materi dan gerakan khususnya pada teknik shooting lay up, mempraktekkan berbagai variasi teknik dasar salah satu permainan bola basket. Modifikasi permainan dalam sebuah pembelajaran penting untuk dilakukan agar siswa lebih aktif berpatisipasi dalam mengikuti kegiatan pembelajaran, meningkatkan percaya diri kegembiraan, kerjasama dan tanggung jawab siswa. Modifikasi peralatan juga dapat memudahkan dalam permainan bola basket. Modifikasi dapat membuat guru lebih mudah dalam menyajikan materi.

\section{Simpulan}

Berdasarkan hasil penelitian yang telah didapat maka diperoleh kesimpulan sebagai berikut ini. Data hasil evaluasi Ahli Media diperoleh rata-rata validitas produk media audio visual yang berbentuk video modifikasi permainan lay up dalam pembelajaran bola basket sebesar 95\% yang menjelaskan bahwa produk sangat valid dan sangat layak untuk digunakan. Dari data hasil evaluasi Ahli Pembelajaran Pendidikan Jasmani diperoleh rata-rata validitas produk media audio visual yang berbentuk video modifikasi permainan lay up dalam pembelajaran bola basket sebesar $84 \%$ yang menjelaskan bahwa produk cukup valid dan layak untuk digunakan. Dari data hasil evaluasi Ahli Basket diperoleh rata-rata validitas produk media audio visual yang berbentuk video modifikasi permainan lay up dalam pembelajaran 
bola basket sebesar 98\% yang menjelaskan bahwa produk sangat valid dan sangat layak untuk digunakan.

\section{Daftar Rujukan}

Ahmadi, N. (2007). Permainan bola basket. Surakarta: Era Intermedia.

Cahyanto, A. G. I. (2015). Pengaruh Modifikasi Permainan Terhadap Hasil Belajar Passing Atas Bolavoli (Studi Pada Siswa Kelas VIIC Smpn 1 Tulangan Kabupaten Sidoarjo).Jurnal Pendidikan Olahraga dan Kesehatan, 3(3).

Mulyasa, E. (2007). Standar kompetensi dan sertifikasi guru. Bandung: PT. Remaja Rosdakarya.

Husdarta, S. H. (2011). Manajemen Pendidikan Jasmani. Bandung: Alfabeta.

Suhardita, K. (2011). Efektivitas penggunaan teknik permainan dalam bimbingan kelompok untuk meningkatkan percaya diri siswa. Edisi khusus, 1, 127-138.

Kristiyandaru, A. (2010). Manajemen pendidikan jasmani dan olahraga. Surabaya: Unesa University Press.

Kurniawan, D. (2015). Pengaruh Modifikasi Permainan Bolavoli Terhadap Kerjasama Siswa Pada Pembelajaran Pendidikan Jasmani, Olahraga Dan Kesehatan (Studi Pada Siswa Kelas X Boga 1 SMKN 3 Probolinggo). Jurnal Pendidikan Olahraga Dan Kesehatan, 3(1). 20-24.

Muarifin, M. (2009). Dasar-Dasar Pendidikan Jasmani Dan Olahraga. Malang: Universitas Negeri Malang.

Ilhamsyah, R. (2018). Pengembangan model permainan lay up dalam pembelajaran bolabasket untuk kelas VIII SMP Negeri 1 Krejengan Kabupaten Probolinggo (Doctoral dissertation, Universitas Negeri Malang).

Harni, S., \& Tarjiah, I. (2018). Implementasi Teori Behaviorisme dalam Membentuk Disiplin Siswa SDN Cipinang Besar Utara 04 Petang Jatinegara Jakarta Timur. Profesi Pendidikan Dasar, 5(2), 127-138.

Sunarsih, S, Dkk. (2007). Penjas Orkes Untuk SD Kelas VI. Jakarta: Erlangga. 